ORNL/TM-2019/1127

CRADA/NFE-16-06356

\title{
CRADA Final Report: Development of Opposed-Piston Variable Compression Ratio Engine for Automotive Applications
}

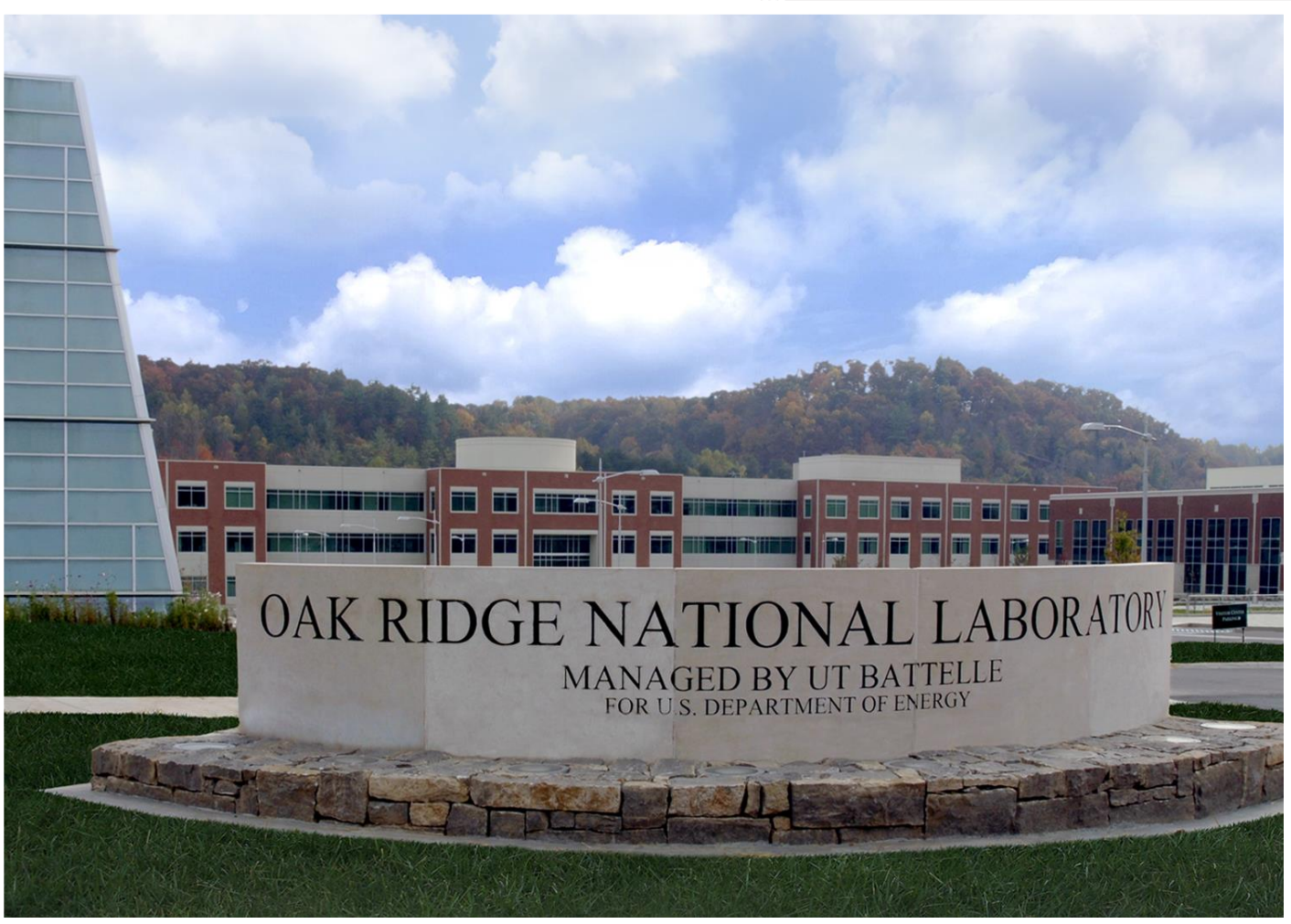

K. Dean Edwards Charles E. A. Finney (ORNL) Clayton Naber Siddhartha Banerjee Michael Willcox (Pinnacle Engines)

February 2019 


\section{DOCUMENT AVAILABILITY}

Reports produced after January 1, 1996, are generally available free via US Department of Energy (DOE) SciTech Connect.

Website http://www.osti.gov/scitech/

Reports produced before January 1, 1996, may be purchased by members of the public from the following source:

National Technical Information Service

5285 Port Royal Road

Springfield, VA 22161

Telephone 703-605-6000 (1-800-553-6847)

TDD 703-487-4639

Fax 703-605-6900

E-mail info@ntis.gov

Website http://www.ntis.gov/help/ordermethods.aspx

Reports are available to DOE employees, DOE contractors, Energy Technology Data Exchange representatives, and International Nuclear Information System representatives from the following source:

Office of Scientific and Technical Information

PO Box 62

Oak Ridge, TN 37831

Telephone 865-576-8401

Fax 865-576-5728

E-mail reports@osti.gov

Website http://www.osti.gov/contact.html

This report was prepared as an account of work sponsored by an agency of the United States Government. Neither the United States Government nor any agency thereof, nor any of their employees, makes any warranty, express or implied, or assumes any legal liability or responsibility for the accuracy, completeness, or usefulness of any information, apparatus, product, or process disclosed, or represents that its use would not infringe privately owned rights. Reference herein to any specific commercial product, process, or service by trade name, trademark, manufacturer, or otherwise, does not necessarily constitute or imply its endorsement, recommendation, or favoring by the United States Government or any agency thereof. The views and opinions of authors expressed herein do not necessarily state or reflect those of the United States Government or any agency thereof. 
ORNL/TM-2019/1127

CRADA/NFE-16-06356

Energy and Transportation Sciences Division

\title{
CRADA FINAL REPORT:
}

\section{DEVELOPMENT OF OPPOSED-PISTON VARIABLE COMPRESSION RATIO ENGINE FOR AUTOMOTIVE APPLICATIONS}

\author{
K. Dean Edwards \\ Charles E. A. Finney \\ (Oak Ridge National Laboratory) \\ Clayton Naber \\ Siddhartha Banerjee \\ Michael Willcox \\ (Pinnacle Engines, Inc.)
}

Date Published:

February 2019

\author{
Prepared by \\ OAK RIDGE NATIONAL LABORATORY \\ Oak Ridge, Tennessee 37831-6283 \\ managed by \\ UT-BATTELLE, LLC \\ for the \\ US DEPARTMENT OF ENERGY \\ under contract DE-AC05-00OR22725
}

Approved for Unlimited Public Release 


\begin{abstract}
Pinnacle Engines, Inc., and researchers at Oak Ridge National Laboratory (ORNL) collaborated under the DOE Small Business Voucher program to perform high-fidelity engine simulations of Pinnacle's unique opposed-piston engine. In addition to the opposed-piston architecture, Pinnacle's design includes features such as variable valve timing and compression ratio which provide the potential for improved performance, efficiency, and emissions but also introduce many degrees of freedom in design and operation. The impact and complex interactions of these design and operating parameters must be well understood to direct and optimize the final design. Using DOE's flagship supercomputing resource, Titan, the team was able to perform an extensive set of numerical engine simulations to explore the impact of these parameters on predicted engine performance. Based on the learnings from this study, Pinnacle will build and experimentally evaluate a prototype engine for light-duty gasoline applications.
\end{abstract}

\title{
INTRODUCTION
}

Pinnacle Engines, Inc. has developed a unique, opposed-piston, four-stroke engine design with reciprocating sleeve valves, variable valve timing (VVT), and continuously variable compression ratio (VCR). The key features of this design are intended to provide potential for improved performance, efficiency, and emissions when compared to conventional light-duty gasoline and diesel engine designs. In particular, the opposed piston architecture incurs less heat loss and allows phasing motion of the two pistons to maximize work extraction efficiency over the engine operating range. The VCR mechanism allows smooth transition between high compression ratio operation at low engine loads to maximize efficiency and low compression ratio operation at high loads to mitigate engine knock. The Pinnacle design provides higher in-cylinder turbulence and unique bulk motion mixture control enabling use of high-efficiency, highly dilute, low-temperature combustion (LTC) approaches. Pinnacle's first generation 110-cc lean-burn LTC engine has been demonstrated to provide significant improvements in performance, efficiency, and emissions over existing comparable-sized engines on the market. Based on this success, Pinnacle is developing a multi-cylinder, 1.2-L gasoline-engine for light-duty passenger vehicles.

Under the DOE Small Business Voucher program, Pinnacle Engines teamed with researchers at ORNL to perform high-fidelity numerical engine simulations to better understand the impact of key design and operating parameters on overall engine performance, efficiency, and emissions. A design of simulation experiments (DoSE) was developed to sample the impact of a large number of design and operating parameters such as piston crown shape, port design, exhaust gas recirculation (EGR) level, spark timing, compression ratio, valve timing, engine speed, and engine load. Using metamodeling approaches, results from the DoE simulations were used to develop response models for desired performance metrics such as combustion phasing, efficiency, knock occurrence, emissions, etc. The number of simulations needed to adequately cover the DoE and the level of detail needed for each simulation would require years of compute time on conventional computing resources. The use of Titan, DOE's flagship HPC resource, enabled the team to perform 100s of parallel simulations and reduce the total computational time down to a few months. Learnings from this effort are expected to help Pinnacle further improve the design of their light-duty gasoline engine.

\section{STATEMENT OF OBJECTIVES}

The goal of this effort was to gain key insight into the impact of key design and operating parameters for Pinnacle's opposed-piston engine design on overall performance and emissions. This improved understanding is expected to guide design and development of a 1.2-L gasoline engine. Specifically, 
large ensembles of detailed computational fluid dynamics (CFD) engine simulations were performed on the Titan supercomputer at ORNL to quickly complete a DoSE study consisting of over 1000 samples. Results from this study will provide key insight to complex design interactions and sensitivities accelerating the design process.

\section{BENEFITS TO THE FUNDING DOE OFFICE'S MISSION}

This project was supported under the DOE Small Business Voucher program which enables American small businesses to collaborate with National Laboratory researchers and access DOE's world-class technical resources to address critical technical challenges they face in development of their advanced energy products. In addition, the work performed directly supports the DOE Vehicle Technologies Office goals for accelerating the development of advanced transportation engines capable of meeting increasingly stringent fuel economy and emissions regulations.

\section{TECHNICAL DISCUSSION OF WORK PERFORMED BY ALL PARTIES}

Through the partnership with ORNL under the DOE Small Business Voucher program, Pinnacle Engines was able to complete vital simulations to provide greater understanding of the impact and interactions of key design and operating parameters enabling analysis-led design and development of their 1.2-L, 3cylinder, 4-stroke, dilute-combustion, spark-ignited gasoline, opposed-piston engine design (see Figure 1). Unique features of Pinnacle's engine design provide potentially significant improvements in performance, efficiency, and emissions compared to conventional gasoline engines. However, this design also presents a large number of degrees of freedom in terms of design and operating parameters. The impact and complex interactions of these parameters needs to be thoroughly understood to guide development of a fully optimized design. The use of high-fidelity engine simulations in the design process to supplement costly and lengthy experimental efforts requiring extensive hardware development and modifications is vital for small businesses such as Pinnacle to become competitive in the transportation sector.

For this effort, simulations were performed using a previously developed, high-fidelity model of the Pinnacle engine concept using the commercially available CONVERGETM CFD software package. An extensive DoSE with over 1000 samples was developed targeting key design and operating parameters including piston crown shape, port design, EGR level, spark timing, compression ratio, valve timing, etc. To acquire the computing resources necessary to complete the simulation task, a Director's Discretionary project on Titan at the Oak Ridge Leadership Computing Facility (OLCF) was proposed and awarded under OLCF's ACCEL Industrial Partnership program. Results from the CFD simulations were used to construct a set of low-order response models (or metamodels) mapping the response of key performance metrics (such as combustion phasing and efficiency, cycle efficiency, occurrence of knock, emissions, etc.). The low-order metamodels retain the fidelity of the higher-order CFD simulations but can be used to rapidly explore a much wider range of design and operation options to accelerate design optimization. A schematic overview of this process is shown in Figure 2. 


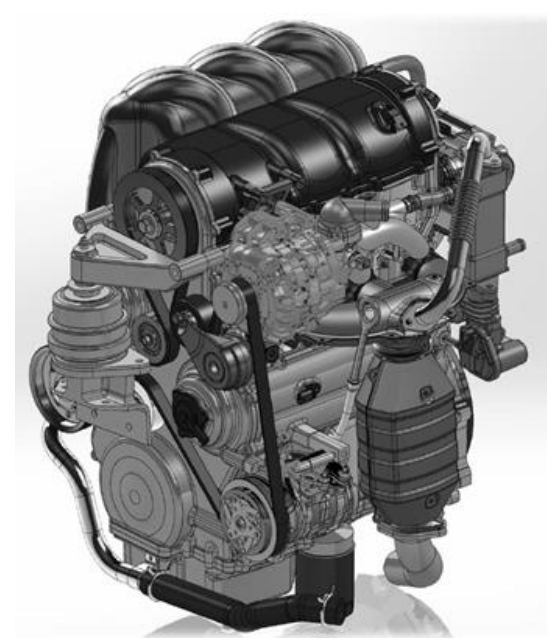

Figure 1: Computer-aided design model of Pinnacle's 1.2-L, 3-cylinder, 4-stroke, spark-ignited, gasoline opposed-piston engine.

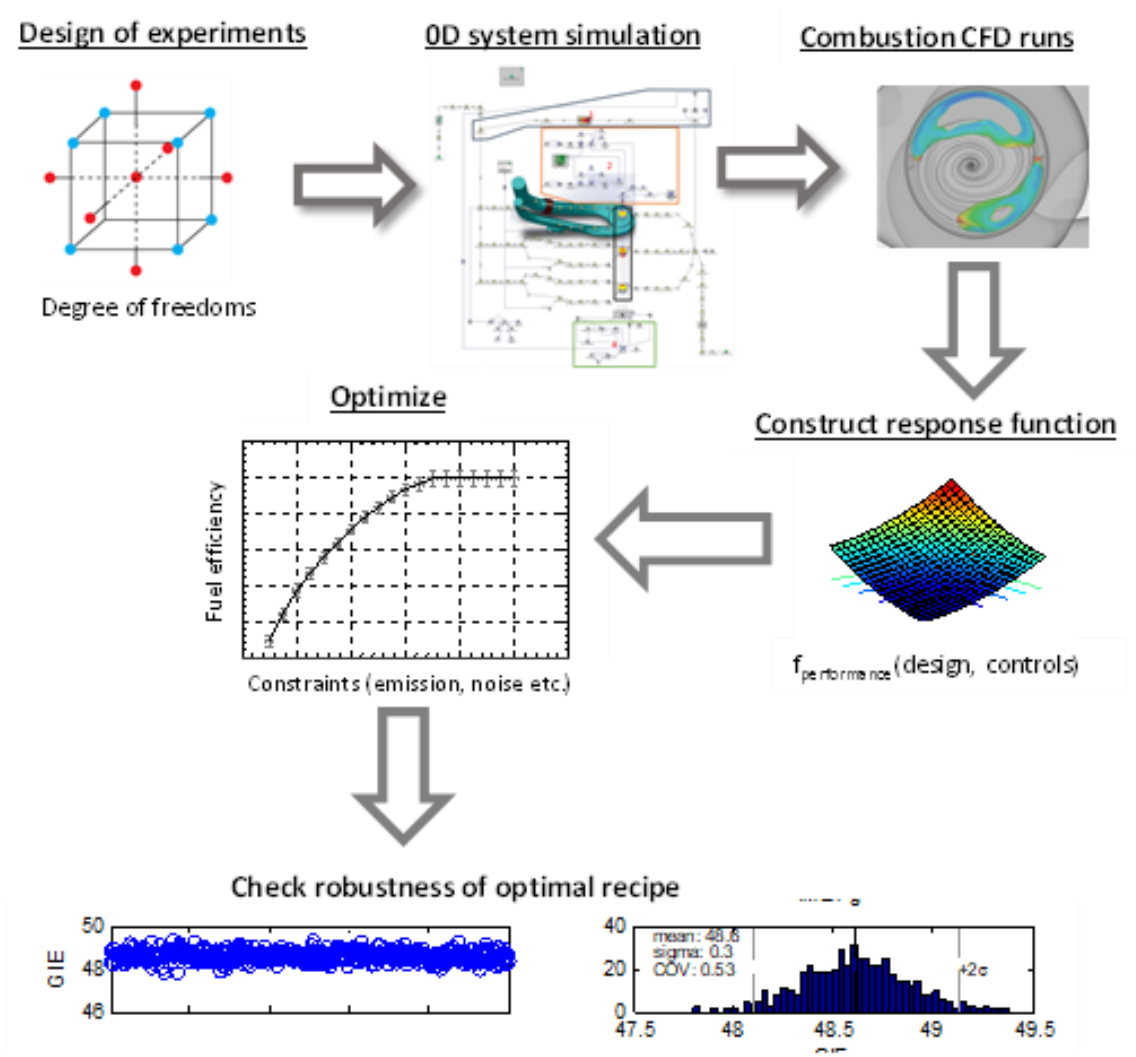

Figure 2. Design and control optimization using model-based prediction [Banerjee, et al. (2018)].

A detailed overview of the work performed and the results obtained during this study was recently published [Banerjee, et al. (2018)]. In summary, the following conclusions were drawn. The enhanced in-cylinder mixing produced by the unique Pinnacle design enhanced dilution tolerance of LTC operation and supports dilute gasoline combustion. Selection of certain key design parameters was confirmed to enable manipulation of flame dynamics to improve combustion stability. Continuously variable 
compression ratio enabled wider operating limits with enhanced performance through high compression ratios for high efficiency cruise and low compression ratios to mitigate knock at high load conditions.

\section{SUBJECT INVENTION}

No subject inventions were developed during this effort.

\section{COMMERCIALIZATION POSSIBILITIES}

Pinnacle Engines, Inc., plans to bring their light-duty engine design to production by 2020 for natural gas applications and by 2023 for gasoline applications.

\section{PLANS FOR FUTURE POSSIBILITIES}

Based on the learnings from this project, Pinnacle Engines is building a prototype engine to conduct experimental testing and evaluation. Results from those efforts will inform further model refinements and additional parameter studies. Additional potential efforts including analysis of cyclic variability have also been discussed. Future pursuit of these potential efforts will be dependent upon available funding opportunities.

\section{CONCLUSIONS}

Through this project under the DOE Small Business Voucher program in partnership with ORNL, Pinnacle Engines was able to successfully perform over 1000 high-fidelity numerical simulations of their opposed-piston engine. These simulations represent a detailed DoSE study to investigate the impact and interactions of key design and operating parameters. Using the HPC resources of Titan, the simulations (which would have taken years to complete on convention computing resources) were completed in under one year enabling the results to inform and guide the design and development of Pinnacle's prototype gasoline engine.

\section{ACKNOWLEDGMENTS}

Efforts by researchers at Oak Ridge National Laboratory were supported by the DOE Vehicle Technologies Office by Gurpreet Singh, Leo Breton, and Michael Weismiller under the DOE Small Business Voucher Program. This research used resources of the Oak Ridge Leadership Computing Facility, which is a DOE Office of Science User Facility supported under Contract DE-AC05$00 \mathrm{OR} 22725$. 


\section{REFERENCES}

S Banerjee, C Naber, M Willcox, CEA Finney, KD Edwards (2018). High performance computing and analysis-led development of high efficiency dilute opposed-piston gasoline engine. ASME Journal of Engineering for Gas Turbines and Power. 140:10. 
